\title{
Strategies for Avoiding Hospitalization of Patients with AECOPD
}

\author{
Sean P. O'Reilly
}

Published online: 16 October 2013

(C) Springer Science+Business Media New York 2013

\begin{abstract}
COPD is increasing in prevalence worldwide and results in substantial social and economic burdens. Exacerbations of COPD lead to accelerated decline of lung function, increased morbidity and mortality, and account for a substantial portion of the costs associated with this disease. Both pharmacologic and nonpharmacologic interventions can reduce exacerbation and hospitalization due to COPD. Safe alternatives to hospitalization for AECOPD are being developed but are not yet widely available.
\end{abstract}

Keywords COPD - AECOPD - Hospitalization · Inhaled corticosteroids $\cdot$ Exacerbation $\cdot$ Bronchodilator

\section{Introduction}

COPD is a leading cause of morbidity and mortality worldwide and is an increasing and substantial economic and social burden [1,2]. The prevalence of COPD is expected to increase in the coming decades as exposure to tobacco smoke, indoor and outdoor air pollution, and the burning of wood or other biomass fuels continues [3]. The economic burden of COPD in the US is estimated at direct costs of $\$ 29.5$ billion and indirect costs of $\$ 20.5$ billion [4]. Acute exacerbation of COPD (AECOPD) is marked by an acute increase in symptoms beyond normal day to day variation. Acute exacerbation affects the burden of COPD by accelerating the decline in lung function, reducing the

\footnotetext{
S. P. O’Reilly $(\bowtie)$

Division of Pulmonary, Allergy, and Critical Care Medicine,

UMassMemorial Healthcare, University of Massachusetts

Medical School, 55 Lake Avenue North, S6-836A, Worcester,

MA 01655, USA

e-mail: sean.oreilly@umassmemorial.org
}

ability to perform daily physical activities, and reducing quality of life $[5,6,7 \bullet \bullet, 8]$. AECOPD is responsible for as much as 35-84 \% of COPD-related healthcare expenses [9-11]. Patient outcomes after COPD exacerbation requiring hospitalization are also dismal, with a two year mortality of $26 \%$ and five year mortality of $55 \%$ [12].

AECOPD results in over 1.5 million emergency department (ED) visits in the US each year. Here the decision must be made regarding inpatient or outpatient treatment, and increasing effort is being made to reduce expensive inpatient care [13]. Once in the ED, no intervention has been shown to reduce hospitalization but common therapy includes increased use of bronchodilators, corticosteroids, and antibiotics [14]. Indications for hospital admission include shortness of breath unresponsive to initial treatment, hypoxemia, worsening hypercapnia, altered mental status, significant comorbid illnesses, symptoms severe enough to prevent necessary activities of daily life, and poor home social support mechanisms [15].

\section{Current Research}

Prevention of AECOPD and the hospitalization associated with it are extremely important. Strategies to reduce exacerbation and hospitalization can be divided into pharmacologic and non-pharmacologic methods.

The most rigorous and comprehensive data available on the topic of preventing exacerbation and hospitalization for AECOPD are those for pharmacologic intervention. Given the heterogeneity of the patient population, with some patients having frequent exacerbation and others none, the best methods for reporting and analyzing the effect of intervention on reduction of AECOPD are controversial $[16,17]$. The methods used to measure AECOPD outcome must be analyzed and taken into account when interpreting 
the findings of individual studies. The Global Initiative for Chronic Obstructive Lung Disease [7••], or GOLD, is an organization which has brought together international experts and organizations, for example the National Heart, Lung, and Blood Institute and the World Health Organization, to increase awareness of and to provide consensus guidelines for the prevention and management of COPD.

Inhaled corticosteroids (ICS) have been examined in COPD, given the contribution of airway inflammation to the disease process. Numerous studies have revealed significant reductions in AECOPD with ICS use but the statistical methods used to determine the magnitude of this reduction have often been criticized [18]. ICS have also often been included with other bronchodilator agents in studies of incidence AECOPD and many of these studies allowed patients to be on ICS before enrollment as long as they stopped them before study entry. This can affect study results given the increased risk of AECOPD when patients taking ICS for stable COPD discontinue them [19]. In the ISOLDE study, 751 patients were randomized to inhaled fluticasone or placebo, after both a washout period for those already on ICS, and a 14 day course of systemic prednisolone, and followed for the next three years. The TORCH trial compared a combination of fluticasone and salmeterol with fluticasone alone, salmeterol alone, or placebo for 875 patients over a three-year period. The ISOLDE study reported a $25 \%$ reduction and the TORCH trial reported a $19 \%$ reduction in AECOPD with ICS [20, 21]. A Cochrane review in 2012 concluded that ICS are effective in reducing AECOPD by from 8 to $30 \%$ compared with placebo [22]. Hospitalization for COPD was not significantly reduced in any of the ICS trials. Concern over reports of an increased incidence of pneumonia in patients using ICS have been tempered by other studies showing no increase [23] or at least reassurances that pneumoniarelated mortality and overall mortality are not increased [24]. From available evidence, use of ICS can help reduce exacerbation but, alone, does not seem to clearly reduce hospitalization for AECOPD.

Long-acting beta agonists have been evaluated for reduction of AECOPD, with conflicting results. The TORCH trial demonstrated that annual exacerbation was $15 \%$ lower when patients used salmeterol compared with placebo. The TRISTAN study was a randomized, doubleblinded study in which 1,465 patients received a combination of fluticasone and salmeterol, fluticasone alone, salmeterol alone, or placebo. In this study, salmeterol was shown to reduce AECOPD by $20 \%$ and to reduce the number of patients requiring systemic corticosteroids [25]. Previous studies evaluating fomoterol use with placebo did not reveal a reduction in overall AECOPD or severe exacerbation requiring systemic corticosteroids [26, 27]. The studies of fomoterol suffered from high dropout in the placebo and treatment arms and were small studies, which limits their conclusions.

The combination of an inhaled corticosteroid with a long-acting beta agonist has been shown to be more advantageous in reducing AECOPD. In the TRISTAN study, fluticasone and salmeterol reduced AECOPD by $25 \%$ and reduced the number of patients requiring systemic corticosteroids by $39 \%$ [27]. Despite these impressive reductions in exacerbation, hospitalization was not reduced, possibly because of the small size of the study and low exacerbation observed. In the TORCH trial, the combination of fluticasone with salmeterol reduced AECOPD by $25 \%$ and hospitalization was reduced by $17 \%$ compared with placebo or either fluticasone or salmeterol alone [21].

The effect of long-acting antimuscarinic agents in reducing AECOPD has also been examined. Tiotropium and aclidinium are the two agents currently available in the US. To date, the only study whose primary endpoint was reduction in AECOPD was conducted by Niewoehner et al. [28] among 1,879 patients with moderate to severe COPD. A reduction in acute exacerbation (27.9 vs $32.3 \%$ ) was seen, but a trend toward lower hospitalization (7.0 vs $9.4 \%)$ did not reach statistical significance. $(p=0.056)$. The understanding potential long-term impacts on function with tiotropium (UPLIFT) study was the largest study to date, with nearly 6,000 patients enrolled and randomized to either placebo or tiotropium. Patients were allowed to use any other inhaled medications except other anticholinergics. This study demonstrated a $14 \%$ reduction in AECOPD but mean hospitalization was not significantly reduced [29]. Aclidinium has shown equivalence with tiotropium in improvement in $\mathrm{FEV}_{1}$ and can improve symptoms in COPD, but has not been evaluated for reduction of AECOPD or hospitalization as a result of AECOPD.

Several studies have examined which agent best reduces the incidence of AECOPD. In the INSPIRE trial, 1,323 patients with a previous exacerbation and predicted $\mathrm{FEV}_{1}$ less than $50 \%$ were randomized to either tiotropium or fluticasone with salmeterol. This study demonstrated no significant difference in either acute exacerbation or hospitalization because of COPD, although more antibiotics were used in the fluticasone with salmeterol group and more systemic steroids were used in the tiotropium group [30]. In the POET-COPD trial, tiotropium was compared with salmeterol alone among 7,376 patients with moderate to severe COPD. Tiotropium reduced overall AECOPD and reduced the number of patients who required hospitalization by $27 \%$ [31]; it was not a pure head-to-head comparison, because many patients also were also taking ICS. Use of triple therapy has also been examined. Aaron et al. demonstrated that the use of tiotropium, fluticasone, and 
salmeterol together, compared with tiotropium alone, reduced hospitalization for AECOPD among 449 patients with moderate to severe COPD. The overall proportion of patients experiencing an exacerbation of COPD was no different among the treatment groups, which included tiotropium alone, tiotropium plus salmeterol, and tioptropium, salmeterol, and fluticasone, but this study suggests that triple therapy can help reduce severe exacerbation which require hospitalization [32].

Phosphodiesterase-4 (PDE-4) is the main enzyme involved in cAMP metabolism in immune and inflammatory cells, and inhibition of this enzyme inhibits the proinflammatory actions of most of these cell types [33-35]. Inconsistent clinical performance and significant side effects, mainly gastrointestinal, have limited mainstream use of these agents for COPD. Recently, roflumilast, a PDE-4 inhibitor with a more favorable benefit-to-side effect ratio has become available. The first randomized, controlled study compared placebo with roflumilast at either 250 or $500 \mu \mathrm{g}$ dose, and showed that $500 \mu \mathrm{g}$ roflumilast reduced the risk of AECOPD, but exacerbation requiring systemic steroids or hospitalization was no different, although the study was not powered to investigate this outcome [36]. A subsequent study by Caverley et al. randomized 1,514 patients with COPD to roflumilast 500 $\mu \mathrm{g}$ or placebo and followed them for a year. Although mean incidence of moderate to severe exacerbation was not statistically different, use of systemic corticosteroids was $18 \%$ lower in the roflumilast group [37]. On the basis of subgroup analysis in this study suggesting a larger benefit to patients with more severe airflow limitation and frequent exacerbation, a prospective randomized trial was conducted among 3,091 patients with GOLD III/IV disease with bronchitic symptoms and exacerbation in the previous year; it was found that moderate to severe exacerbation was reduced by $17 \%$ [38]. Hospitalization for AECOPD was not reduced, however. The ongoing REACT (roflumilast in the prevention of COPD exacerbation while taking appropriate combination therapy) study is evaluating addition of roflumilast to different combinations of inhalation therapy, including triple therapy [39]. Until complete, the utility of roflumilast lies in reducing exacerbation, but not in reducing hospitalization for COPD. Side effects remain troublesome; they include diarrhea, nausea, and weight loss, which can be intolerable for some patients.

Macrolide antibiotics have anti-inflammatory and immune-modulating effects in addition to their antimicrobial effects and have been studied for prevention of AECOPD [40]. Erythromycin has been shown to reduce the incidence of AECOPD, but not hospitalization, in several small studies [41, 42]. Azithromycin $250 \mathrm{mg}$ daily was added to usual care in a large, randomized controlled study of 1,142 patients and reduced AECOPD by $27 \%$ and was associated with a trend toward lower hospitalization [43•]. This came at a price, increased incidence of hearing loss and greater incidence colonization by macrolideresistant organisms. Thus, macrolides seem to reduce AECOPD but do not clearly reduce hospitalization.

Theophylline is a methylxanthine which has bronchodilator properties. At low doses it is believed to have antiinflammatory and immunomodulatory action [44]. There are surprisingly few data on its effect on exacerbation frequency in COPD. One large retrospective study showed that users of theophylline had a small reduction in exacerbation frequency compared with users of long-acting beta- 2 agonists but more exacerbation than users of ICS [45]. In the only randomized controlled study, conducted by Zhou et al., 110 patients were randomized to either slow-release theophylline, $100 \mathrm{mg}$ by mouth twice daily, or placebo over the course of a year; the study showed that theophylline could reduce the frequency and duration of exacerbation. Before study enrollment the patients enrolled were primarily being treated with short-acting beta-agonists alone for COPD control. Theophylline was attractive because of ease of administration and low cost [46]. GOLD guidelines for the treatment of COPD note this reduction in exacerbation frequency but the guidelines do not recommend theophylline when other bronchodilators are available because of its poor action as a bronchodilator and higher potential for toxicity [5].

Mucolytics have also been examined for treatment of COPD. $N$-Acetylcysteine, a mucolytic agent with direct and indirect anti-inflammatory and antioxidant properties, is the most widely studied mucolytic in COPD. A Cochrane analysis in 2012 demonstrated that mucolytics can slightly reduce AECOPD and in the two studies that have examined this secondary outcome hospitalization decreased (OR 0.70, CI 0.49-1.01). Also, for hospitalized patients, duration of hospitalization might be reduced [47-49]. Mucolytics remain controversial and cannot be universally recommended, but side effects seem to be minimal and future studies might reveal subgroups of COPD patients, for example those with frequent exacerbation, who might benefit most.

Pulmonary rehabilitation can improve quality of life in COPD and its effect on exacerbation and hospital admission has been examined with mixed results. Six weeks of pulmonary rehabilitation was compared with placebo in one randomized controlled study of 200 patients, and showed that although respiratory-related hospitalization was no different overall, the incidence of exacerbation per patient in the rehabilitation group was significantly reduced and duration of hospitalization decreased by half [50]. A smaller study among 60 Spanish patients who received one year of pulmonary rehabilitation versus usual care revealed a significant reduction in the number of exacerbations per 
patient. Although a trend toward less hospitalization was seen, it was not significant [51]. A Cochrane analysis in 2011 reviewed nine studies on 432 patients who had recently experienced exacerbation of COPD showed that pulmonary rehabilitation programs after AECOPD could reduce subsequent hospital admissions significantly with an odds ratio of 0.22 and number needed to treat of four. It also significantly reduced mortality [52•]. A more recent study of 60 patients in China was unable to reproduce these results and, despite an improvement in health-related quality of life, pulmonary rehabilitation did not reduce emergency room visits or hospital admissions for COPD [53]. It has been proposed that the effect on ED visits and hospital admissions was not seen because this program was limited to exercise and did not include education and access to action plans [54].

Mortality in AECOPD has been most closely linked to significant hypercapnia with respiratory acidosis, and to the presence of co-morbidities at hospital admission [52, 55 , 56]. Managing patients without these risk factors at home has gained more attention with initial studies showing promise in reducing ED visits and hospitalization. Patients often delay reporting acute exacerbation to their physicians, which can lead to longer exacerbation and more frequent hospitalization [57]. Evidence indicates that early reporting of AECOPD to medical practitioners can reduce duration of symptoms, and that failure to report AECOPD symptoms early can lead to increased hospitalization [58]. Bourbeau et al. randomized 190 patients with at least one AECOPD within the past year to either usual care or a self management program. The program included a series of teaching modules, undertaken at home, which included education about the disease, energy conservation and relaxation techniques, healthy lifestyle counseling, which included a section on tobacco cessation, an action plan to be used for acute exacerbation, and a basic exercise program. Patients had telephone access to case managers with expertise in COPD throughout the study. A $39.8 \%$ reduction in hospitalization for AECOPD was noted in the intervention group. Intervention patients were also $41 \%$ less likely to have an ED visit or to have to see another physician at an urgent visit [59]. Casas et al. [60] showed that patients randomized during a hospitalization for AECOPD to either a disease-management program, including a combination of education sessions, home visits, followup telephone calls, and access to an action plan for acute exacerbation, had a significantly fewer readmissions to the hospital for COPD during the next year without any difference in mortality. Rice et al. demonstrated, among a larger cohort of VA patients, that a simpler self management plan could lead to a similar dramatic reduction in hospitalization for AECOPD. The intervention group in this study received a one page handout on important topics in COPD management, attended a $1-1.5 \mathrm{~h}$ teaching session conducted by a case manager with respiratory expertise, and had an action plan combined with prewritten prescriptions for corticosteroids and antibiotics, monthly phone calls from a case manager, and $24 \mathrm{~h}$ access to a VA telephone hotline. Again, the intervention group was $31 \%$ less likely to be hospitalized and $51 \%$ less likely to visit an emergency room for an AECOPD [61]. Not all studies have shown such promise. Studies have varied in the quality of the self management program, patient population, and duration of follow-up; no reduction in hospitalization had been observed for the largest previous cohort [62]. A recent study by Fan et al. was stopped early, after fewer than half its intended patients had been enrolled, because of a finding of excess mortality in the intervention group. This intervention included patient education sessions designed to address key behavioral and environmental behavior which would help best contribute to patient well being and again focused on smoking cessation, breathing, and cough techniques to conserve energy, self-monitoring of symptoms, and prescriptions to have antibiotics and corticosteroids on hand to begin at the sign of an exacerbation. This study was designed to study the incidence of hospitalization in the two groups, with secondary outcomes including quality of life and mortality. Although the incidence of comorbid cardiovascular disease was higher in the intervention group, it was unclear whether this was responsible for the increased mortality. At the time the trial was stopped, no difference in hospitalization for COPD was noted [63]. Although self-management programs seem to hold promise, they are not universally available and require significant investment in time and resources in outpatient pulmonary specialty clinics; they may become more widespread as reimbursement models change.

Previous reviews of wide-ranging medical conditions suggested that so-called "Hospital at home" programs could provide equivalent outcomes with reduced cost and improved patient experience [64]. These programs involve patients treated at home directly from an urgent care center or ED or those discharged quickly from an inpatient area. A recent Cochrane review of hospital at home programs for AECOPD revealed that among the studies included there was a significant improvement in hospital readmission, with no difference, or perhaps a small reduction, in mortality [65]. Health-related quality of life, lung function, and patient satisfaction also did not seem to differ, although the confidence in the quality of data for these secondary outcomes was limited. These studies randomized patients with AECOPD to either early discharge from the hospital or ED to home or to usual inpatient care within $72 \mathrm{~h}$ of presentation. The home intervention included frequent home visits by nursing staff, inhaled bronchodilators, systemic corticosteroids and antibiotics, and additional telephone follow-up. 
Direct economic costs reported in three studies suggested overall reduction in cost, even when not taking into account health savings from reduced exacerbation, quality of life, and absence from work. Again, the evidence was of poor quality and is likely to vary significantly between countries, so no direct conclusion can be made with available evidence. Management of appropriate patients at home is feasible, is potentially equally safe and satisfactory for patients, and could reduce costs associated with COPD, but access to such intensive home-management programs is very limited.

\section{Summary and Conclusions}

Available evidence suggests that pharmacologic intervention, for example long-acting beta-agonists, long-acting muscarinic antagonists, and ICS can reduce the frequency of exacerbation in COPD. Long-acting beta-agonists and long-acting antimuscarinic antagonists seem to reduce hospitalization for AECOPD. Guidelines for the use of macrolide antibiotics, PDE-4 inhibitors, mucolytics, and theophylline are evolving. Pulmonary rehabilitation has great benefits in COPD overall and seems to reduce hospitalization. Self-management and hospital at home programs also hold promise for preventing hospitalization but are not yet widely available.

\section{Compliance with Ethics Guidelines}

Conflict of Interest Sean P. O'Reilly declares that he has no conflict of interest.

Human and Animal Rights and Informed Consent This article does not contain any studies with human or animal subjects performed by the author.

\section{References}

Papers of importance, published recently, have been highlighted as:

- Of importance

- Of major importance

1. Lopez AD, Shibuya K, Rao C, et al. Chronic obstructive pulmonary disease: current burden and future projections. Eur Respir J. 2006;27:397-412.

2. Mathers CD, Loncar D. Projections of global mortality and burden of disease from 2002 to 2030. PLoS Med. 2006;3:e442.

3. Salvi SS, Barnes PJ. Chronic obstructive pulmonary disease in nonsmokers. Lancet. 2009;374:733-43.

4. National Heart, Lung, and Blood Institute. Morbidity and mortality chartbook on cardiovascular, lung, and blood diseases. Bethesda, Maryland: US Department of Health and Human Services, Public Health Service, National Institute of Health. 2009. http://www.nhlbi.nih.gov/resources/docs/cht-book.htm. Accessed 25 May 2013.

5. Donaldson GC, Seemungal TA, Bhowmik A, Wedzicha JA. Relationship between exacerbation frequency and lung function decline in chronic obstructive pulmonary disease. Thorax. 2002; 57(10):847-52.

6. Kanner RE, Anthonisen NR, Connett JE, Lung Health Study Research Group. Lower respiratory illnesses promote FEV1 decline in current smokers but not ex-smokers with mild chronic obstructive pulmonary disease: results from the lung health study. Am J Respir Crit Care Med. 2001;164(3):358-64.

7. • Global Initiative for Chronic Obstructive Lung Disease. Global strategy for the diagnosis, management, and prevention of chronic obstructive pulmonary disease, NHLBI/WHO workshop report. Updated 2013 [Internet]. Bethesda (MD): National Heart, Lung, and Blood Institute; 1998 Apr [updated 2013 Sep]. http:// www.goldcopd.com. Accessed 1 Jul 2013. GOLD guidelines represent the most up to date guidelines on the diagnosis, prevention, and treatment of COPD. Because FEVI alone is a poor descriptor of disease status, the disease impact (symptoms of breathlessness and activity limitation) and frequency of exacerbations take on added importance in the 2013 update, especially in staging disease and guiding therapy.

8. Seemungal TA, Donaldson GC, Paul EA, Bestall JC, Jeffries DJ, Wedzicha JA. Effect of exacerbation on quality of life in patients with chronic obstructive pulmonary disease. Am J Respir Crit Care Med. 1998;157(5pt1):1418-22.

9. Izquierdo JL. The burden of COPD in Spain: results from the confronting COPD survey. Respir Med. 2003;97(suppl C):S71-9.

10. Andersson F, Borg S, Jansson SA, et al. The costs of exacerbations in chronic obstructive pulmonary disease (COPD). Respir Med. 2002;96(9):700-8.

11. Britton M. The burden of COPD in the UK: results from the confronting COPD survey. Respir Med. 2003;97(suppl C):S71-9.

12. Soler-Cataluña JJ, Martínez-García MA, Román Sánchez P, Salcedo E, Navarro M, Ochando R. Severe acute exacerbations and mortality in patients with chronic obstructive pulmonary disease. Thorax. 2005;60(11):925-31.

13. Mannino DM, Homa DM, Akinbami LJ, Ford ES, Redd SC. Chronic obstructive pulmonary disease surveillance: United States, 1971-2000. MMWR Surveill Summ. 2002;51(6):1-16.

14. Stoller JK. Clinical practice. Acute exacerbations of chronic obstructive pulmonary disease. N Engl J Med. 2002;346(13):988-94.

15. American Thoracic Society/European Respiratory Society Task Force. Standards for the diagnosis and management of patients with COPD. Version 1.2. New York: American Thoracic Society; 2004 [updated 2005 September 8]. http://www.thoracic.org/go/ copd. p. 170-5. Accessed 10 May 2013.

16. Suissa S. Statistical treatment of exacerbations in therapeutic trials of chronic obstructive pulmonary disease. Am J Respir Crit Care Med. 2006;173(8):842-6.

17. Marchetti N, Criner G, Albert RK. Preventing acute exacerbations and hospital admissions in COPD. Chest. 2013;143(5): 1444-54.

18. Suissa S, Ernst P, Vandemheen KL, Aaron SD. Methodological issues in therapeutic trials of COPD. Eur Respir J. 2008; 31(5):927-33.

19. Jarad NA, Wedzicha JA, Burge PS, Calverley PM. An observational study of inhaled corticosteroid withdrawal in stable chronic obstructive pulmonary disease. ISOLDE Study Group. Respir Med. 1999;93:161-6.

20. Burge PS, Calverley PM, Jones PW, et al. Randomised, double blind, placebo controlled study of fluticasone propionate in patients with moderate to severe chronic obstructive pulmonary disease: the ISOLDE trial. BMJ. 2000;320:1297. 
21. Calverley PM, Anderson JA, Celli B, the TORCH investigators, et al. Salmeterol and fluticasone propionate and survival in chronic obstructive pulmonary disease. N Engl J Med. 2007; 356(8):775-89.

22. Yang IA, Clarke MS, Sim EH, Fong KM. Inhaled corticosteroids for stable chronic obstructive pulmonary disease. Cochrane Database Syst Rev. 2012;7:CD002991.

23. Sin DD, Tashkin D, Zhang X, et al. Budesonide and the risk of pneumonia: a meta-analysis of individual patient data. Lancet. 2009;374:712.

24. Singh S, Amin AV, Loke YK. Long-term use of inhaled corticosteroids and the risk of pneumonia in chronic obstructive pulmonary disease: a meta-analysis. Arch Intern Med. 2009;169:219.

25. Calverley P, Pauwels R, Vestbo J, the TRial of Inhaled STeroids ANd long-acting beta2 agonists study group, et al. Combined salmeterol and fluticasone in the treatment of chronic obstructive pulmonary disease: a randomised controlled trial. Lancet. 2003;361(9356):449-56.

26. Calverley PM, Boonsawat W, Cseke Z, Zhong N, Peterson S, Olsson H. Maintenance therapy with budesonide and formoterol in chronic obstructive pulmonary disease. Eur Respir J. 2003; 22(6):912-9.

27. Szafranski W, Cukier A, Ramirez A, et al. Efficacy and safety of budesonide/formoterol in the management of chronic obstructive pulmonary disease. Eur Respir J. 2003;21(1):74-81.

28. Niewoehner DE, Rice K, Cote C, et al. Prevention of exacerbations of chronic obstructive pulmonary disease with tiotropium, a once-daily inhaled anticholinergic bronchodilator: a randomized trial. Ann Intern Med. 2005;143:317.

29. Tashkin DP, Celli B, Senn S, the UPLIFT Study Investigators, et al. A 4-year trial of tiotropium in chronic obstructive pulmonary disease. N Engl J Med. 2008;359(15):1543-54.

30. Wedzicha JA, Calverley PM, Seemungal TA, Hagan G, Ansari Z, Stockley RA, the INSPIRE Investigators. The prevention of chronic obstructive pulmonary disease exacerbations by salmeterol/fluticasone propionate or tiotropium bromide. Am J Respir Crit Care Med. 2008;177(1):19-26.

31. Vogelmeier C, Hederer B, Glaab T, the POET-COPD Investigators, et al. Tiotropium versus salmeterol for the prevention of exacerbations of COPD. N Engl J Med. 2011;364(12):1093-103.

32. Aaron SD, Vandemheen KL, Fergusson D, the Canadian Thoracic Society/Canadian Respiratory Clinical Research Consortium and the Canadian Thoracic Society/Canadian Respiratory Clinical Research Consortium, et al. Tiotropium in combination with placebo, salmeterol, or fluticasone-salmeterol for treatment of chronic obstructive pulmonary disease: a randomized trial. Ann Intern Med. 2007;146(8):545-55.

33. Rabe KF. Update on roflumilast, a phosphodiesterase 4 inhibitor for the treatment of chronic obstructive pulmonary disease. Br J Pharmacol. 2011;163:53-67.

34. Houslay MD. Underpinning compartmentalised cAMP signalling through targeted cAMP breakdown. Trends Biochem Sci. 2010;35:91-100.

35. Beghè B, Rabe KF, Fabbri LM. Phosphodiesterase-4 inhibitor therapy for lung diseases. Am J Respir Crit Care Med. 2013; 188(3):271-8

36. Rabe KF, Bateman ED, O'Donnell D, Witte S, Bredenbroker D, Bethke TD. Roflumilast: an oral anti-inflammatory treatment for chronic obstructive pulmonary disease: a randomised controlled trial. Lancet. 2005;366:563-71.

37. Calverley PM, Sanchez-Toril F, McIvor A, Teichmann P, Bredenbroeker D, Fabbri LM. Effect of 1-year treatment with roflumilast in severe chronic obstructive pulmonary disease. Am J Respir Crit Care Med. 2007;176:154-61.

38. Calverley PM, Rabe KF, Goehring UM, Kristiansen S, Fabbri LM, Martinez FJ. Roflumilast in symptomatic chronic obstructive pulmonary disease: two randomised clinical trials. Lancet. 2009;374:685-94.

39. Calverley PM, Martinez FJ, Fabbri LM, Goehring UM, Rabe KF. Does roflumilast decrease exacerbations in severe COPD patients not controlled by inhaled combination therapy? The REACT study protocol. Int J Chron Obstruct Pulmon Dis. 2012;7:375-82.

40. Martinez F, Curtis J, Albert R. Role of macrolide therapy in chronic obstructive pulmonary disease. Int J COPD. 2008; 3:331-50.

41. Suzuki T, Yanai M, Yamaya M, Satoh-Nakagawa T, Sekizawa K, Ishida S, Sasaki H. Erythromycin and common cold in COPD. Chest. 2001;120:730-3.

42. Seemungal T, Wilkinson T, Hurst J, Perera W, Sapsford F, Wedzicha J. Long-term erythromycin therapy is associated with decreased chronic obstructive pulmonary disease exacerbations. Am J Respir Crit Care Med. 2008;178:1139-47.

43. - Albert RK, Connett J, Bailey WC, et al; and the COPD Clinical Research Network. Azithromycin for prevention of exacerbations of COPD. N Engl J Med. 2011;365(8):689-698. This study demonstrates the utility of chronic azithromycin use to prevent exacerbations of COPD. It also raises important issues of side effects such as decreased hearing acuity and increased bacterial resistance to an important class of antibiotics which could have society-wide adverse effects.

44. Sullivan P, Bekir S, Jaffar Z, et al. Anti-inflammatory effects of low-dose oral theophylline in atopic asthma. Lancet. 1994; 343:1006-8.

45. Cyr MC, Beauchesne MF, Lemière C, Blais L. Effect of theophylline on the rate of moderate to severe exacerbations among patients with chronic obstructive pulmonary disease. Br J Clin Pharmacol. 2008;65(1):40.

46. Zhou Y, Wang X, Zeng X, et al. Positive benefits of theophylline in a randomized, double-blind, parallel-group, placebo-controlled study of low-dose, slow-release theophylline in the treatment of COPD for 1 year. Respirology. 2006;11:603-10.

47. Poole P, Black PN, Cates CJ. Mucolytic agents for chronic bronchitis or chronic obstructive pulmonary disease. Cochrane Database Syst Rev. 2012;8:CD001287. doi: 10.1002/14651858. CD001287.pub4.

48. Decramer M, Rutten-van Mölken M, Dekhuijzen PN, et al. Effects of $N$-acetylcysteine on outcomes in chronic obstructive pulmonary disease (Bronchitis Randomized on NAC Cost-Utility Study, BRONCUS): a randomised placebo-controlled trial. Lancet. 2005;365(9470):1552-60.

49. Moretti M, Bottrighi P, Dallari R, et al. The effect of long-term treatment with erdosteine on chornic obstructive pulmonary disease: the EQUALIFE study. Drugs Exp Clin Res. 2004; 30(4):143-52.

50. Griffiths TL, Burr ML, Campbell IA, et al. Results at 1 year of outpatient multidisciplinary pulmonary rehabilitation: a randomised controlled trial. Lancet. 2000;355(9201):362-8.

51. Güell R, Casan P, Belda J, et al. Long-term effects of outpatient rehabilitation of COPD: a randomized trial. Chest. 2000; 117(4):976-83.

52. - Puhan MA, Gimeno-Santos E, Scharplatz M, Troosters T, Walters EH, Steurer J. Pulmonary rehabilitation following exacerbations of chronic obstructive pulmonary disease. Cochrane Database Syst Rev. 2011;10: CD005305. doi:10.1002/ 14651858.CD005305.pub3. An important review demonstrating the effectiveness of a safe, nonpharmacologic intervention, widely available, in improving quality of life and decreasing hospital readmission rates.

53. Ko FW, Dai DL, Ngai J, et al. Effect of early pulmonary rehabilitation on health care utilization and health status in patients hospitalized with acute exacerbations of COPD. Respirology. 2011;16(4):617-24. 
54. Bourbeau J. Preventing hospitalizations for COPD exacerbations: early pulmonary rehabilitation? Respirology. 2011;16(4):579-80.

55. Jeffrey AA, Warren PM, Flenley DC. Acute hypercapnic respiratory failure in patients with chronic obstructive pulmonary lung disease: risk factors and use of guidelines for management. Thorax. 1992;47:37-40.

56. Seneff MG, Wagner DP, Wagner RP, Zimmerman JE, Knaus WA. Hospital and 1-year survival of patients admitted to intensive care units with acute exacerbations of chronic obstructive pulmonary disease. JAMA. 1995;274:1852-7.

57. Wilkinson TMA, Donaldson GC, Hurst JR, Seemungal TAR, Wedzicha JA. Impact of reporting and rarely therapy on outcome of exacerbations of COPD. Am J Respir Crit Care Med. 2004;169:1298-303.

58. Wilkinson TM, Donaldson GC, Hurst JR, Seemungal TA, Wedzicha JA. Early therapy improves outcomes of exacerbations of chronic obstructive pulmonary disease. Am J Respir Crit Care Med. 2004;169:1298-303.

59. Bourbeau J, Julien M, Maltais F, et al;; and the Chronic Obstructive Pulmonary Disease axis of the Respiratory Network Fonds de la Recherche en Santé du Québec and the Chronic Obstructive Pulmonary Disease axis of the Respiratory Network Fonds de la Recherche en Santé du Québec. Reduction of hospital utilization in patients with chronic obstructive pulmonary disease: a disease-specific self-management intervention. Arch Intern Med. 2003;163(5):585-591.
60. Casas A, Troosters T, Garcia-Aymerich J, et al. Integrated care prevents hospitalisations for exacerbations in COPD patients. Eur Respir J. 2006;28(1):123-30.

61. Rice KL, Dewan N, Bloomfield HE, et al. Disease management program for chronic obstructive pulmonary disease: a randomized controlled trial. Am J Respir Crit Care Med. 2010;182(7):890-6.

62. Adams SG, Smith PK, Allan PF, Anzueto A, Pugh JA, Cornell JE. Systematic review of the chronic care model in chronic obstructive pulmonary disease prevention and management. Arch Intern Med. 2007;167:551-61.

63. Fan VS, Gaziano JM, Lew R, et al. A comprehensive care management program to prevent chronic obstructive pulmonary disease hospitalizations: a randomized, controlled trial. Ann Intern Med. 2012;156(10):673-83.

64. Shepperd S, Doll H, Angus RM, Clarke MJ, Iliffe S, Kalra L, Ricauda NA, Wilson AD. Hospital at home admission avoidance. Cochrane Database Syst Rev. 2008;4:CD007491. doi:10.1002/ 14651858.CD007491.

65. Jeppesen E, Brurberg KG, Vist GE, Wedzicha JA, Wright JJ, Greenstone M, Walters JAE. Hospital at home for acute exacerbations of chronic obstructive pulmonary disease. Cochrane Database Syst Rev. 2012;5:CD003573. doi:10.1002/14651858. CD003573.pub2. 